\title{
How effective is acupuncture for reducing pain due to plantar fasciitis?
}

Anandan Gerard Thiagarajah, MMed, FCFPS

\begin{abstract}
INTRODUCTION Plantar fasciitis is a commonly seen outpatient condition that has numerous treatment modalities of varying degrees of efficacy. This systematic review aimed to determine the effectiveness of acupuncture in reducing pain caused by plantar fasciitis.

METHODS Online literature searches were performed on the PubMed and Cochrane Library databases for studies on the use of acupuncture for pain caused by plantar fasciitis. Studies designed as randomised controlled trials and that compared acupuncture with standard treatments or had real versus sham acupuncture arms were selected. The Delphi list was used to assess the methodological quality of the studies retrieved.

RESULTS Three studies that compared acupuncture with standard treatment and one study on real versus sham acupuncture were found. These showed that acupuncture significantly reduced pain levels in patients with plantar fasciitis, as measured on the visual analogue scale and the Plantar Fasciitis Pain/Disability Scale. These benefits were noted between four and eight weeks of treatment, with no further significant reduction in pain beyond this duration. Side effects were found to be minimal.

CONCLUSION Although acupuncture may reduce plantar fasciitis pain in the short term, there is insufficient evidence for a definitive conclusion regarding its effectiveness in the longer term. Further research is required to strengthen the acceptance of acupuncture among healthcare providers.
\end{abstract}

Keywords: acupuncture, plantar fasciitis

\section{INTRODUCTION}

Plantar fasciitis is a commonly seen condition that is considered to be a biomechanical overuse injury due to running or prolonged standing, which creates microtears at the calcaneal enthesis. ${ }^{(1-3)}$ In the United States, it is estimated that more than one million patients suffer from this condition annually, with two-thirds of them visiting their family physicians for it. ${ }^{(1)}$

The diagnosis of plantar fasciitis is clinical; most patients report heel pain that occurs after a period of foot rest, such as when sleeping or sitting. The pain is reduced after taking a few steps, but can get worse if the patient persists with ambulation or prolonged standing. Physical examination usually reveals tenderness over the medial plantar calcaneal region. The condition is self-limiting and treatment is mainly to reduce morbidity rather than to cure it. Plantar fasciitis usually improves within one year, but most patients will seek medical attention for pain relief, as it affects their activities of daily living. ${ }^{(4)}$

Many types of well-established treatments are available for plantar fasciitis, such as physiotherapy, splints, customised insoles, oral analgesia, steroid injections, ultrasonographic therapy and surgery. However, acupuncture, a treatment modality commonly used by traditional Chinese medicine practitioners, is not considered a standard part of the treatment armamentarium. In a local study by Peeraully et al on the use of complementary therapies for hemifacial spasm, it was found that $51 \%$ of 96 patients had tried complementary therapies. ${ }^{(5)}$ Among these patients, $71.4 \%$ had tried acupuncture. In another local study by
Tan et al on the use of complementary and alternative medicine (CAM) by patients with chronic pain, $84 \%$ of 210 patients were found to have used CAM. ${ }^{(6)}$ Among these patients, $49 \%$ had used acupuncture. These studies show that a significant proportion of local patients are willing to accept acupuncture as part of their treatment.

This review aimed to determine the effectiveness of acupuncture in reducing pain caused by plantar fasciitis. We examined the effects of dry needling and electro-acupuncture in plantar fasciitis patients of any age group, provided that the outcome was a documented reduction in reported pain. The comparators selected were standard conservative therapy and sham therapy. Other forms of acupuncture, such as the use of laser or moxibustion, were not included.

\section{METHODS}

A literature search of the PubMed and Cochrane Library databases was conducted for randomised controlled trials (RCTs) that compared acupuncture with standard treatments or had real versus sham acupuncture arms for patients with plantar fasciitis, using the keywords: 'acupuncture' [MeSH] AND 'plantar fasciitis' [MeSH]. Various combinations of the following words were also used to ensure that all possible studies on the subject were identified: 'acupuncture' OR 'electro-acupuncture' OR 'electro acupuncture' OR 'electric acupuncture' OR 'electrical acupuncture' AND 'plantar fasciitis' OR 'plantar fasciosis' OR 'plantar fasciopathy'. Manual searching was additionally 


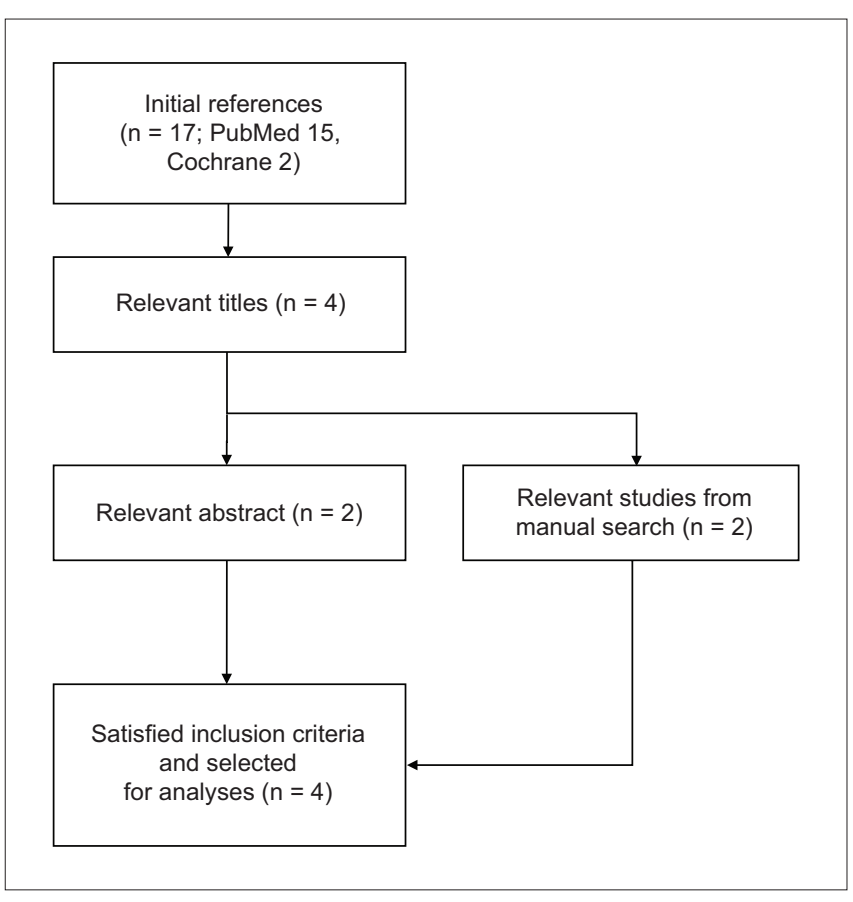

Fig. 1 Flow diagram shows the selection of studies following the literature search.

performed by reviewing references from the identified studies. The inclusion criteria were: (a) RCTs; and (b) treatment that included acupuncture or electro-acupuncture versus standard therapy. The limits applied were studies that involved humans and were published in the English language. The exclusion criteria included: (a) non-randomised and uncontrolled trials; (b) interventions that included other forms of acupuncture, such as laser acupuncture; and (c) controls that included corticosteroid injections. Studies were shortlisted based on how appropriate their titles were. Selected studies were analysed based on their abstracts and reviewed for inclusion according to the above criteria. The full papers of those studies that met the inclusion criteria were retrieved for further analysis.

The Delphi list, which is made up of nine items, was used to assess the quality of the methodology of the studies. ${ }^{(7)}$ Each item was given one point if it received a 'Yes' response and zero points for 'No' or 'Don't know' responses. The denominator was reduced if any item was not applicable. Studies with scores $>75 \%, 50 \%-75 \%$ and $<50 \%$ were deemed to be of good, fair and poor quality, respectively.

\section{RESULTS}

Fig. 1 shows the results of the literature search. In total, 17 studies were obtained following the search, of which 15 were excluded - one was a protocol for a review, three were not RCTs and 11 were on treatment modalities other than acupuncture. Two other studies were found via manual search.

The study by Zhang et $\mathrm{al}^{(8)}$ had a quality score of $88.9 \%$ and was considered to be of good quality. Two studies (Kumnerddee et $\mathrm{al}^{(9)}$ and Karagounis et $\mathrm{al}^{\left({ }^{(10)}\right)}$ had quality scores of $66.7 \%$ and were considered to be of fair quality. The final study by Ebrahim et $\mathrm{al}^{(11)}$ had a quality score of $44.4 \%$ and was considered to be of poor quality. Table I shows the quality analysis of the four studies selected. The key characteristics and findings of these four studies are shown in Table II.

After 4-8 weeks of treatment using acupuncture, all four studies showed significant improvement in pain among patients with plantar fasciitis. ${ }^{(8-11)}$ Zhang et al's study evaluated pain control over a longer period (of up to six months) and showed that the pain-relieving effects of acupuncture were not greater than standard therapy in the longer term. ${ }^{(8)}$ Pooling of results was not possible as the studies retrieved were too heterogeneous in terms of types of acupuncture used, types of controls included and duration of therapy.

\section{DISCUSSION}

The four studies retrieved had varying methods of applying acupuncture therapy. Two studies (Ebrahim et al and Kumnerddee et al) had used electro-acupuncture, which refers to the application of electrical current to acupuncture needles..$^{(9,11)}$ Kumnerddee et al noted that no manual manipulation of the needle was done ${ }^{(9)}$ while Ebrahim et al did not state whether manual manipulation was performed. ${ }^{(11)}$ The other two studies had used dry needling, ${ }^{(8,10)}$ which is standard acupuncture with sterile needles without any electrical current. Both of these studies involved manual manipulation of the needles to obtain the 'Deqi' sensation, which is characterised as a dull ache, numbness or heaviness.

Zhang et al compared acupuncture at real versus sham sites. ${ }^{(8)}$ Both types of sites were distal and contralateral to the area of plantar fasciitis. Participants in the treatment group received needling at the acupoint Daling (PC7), which is located on the palmar side of the forearm at the midpoint of the wrist crease. This acupoint is purported to be specific for heel pain. In addition to heel pain, this acupoint is also used for other painful conditions, such as stomachache, chest or cardiac pain, and headache. Participants in the sham group received needling at the acupoint Hegu (LI4), which is located between the first and second metacarpal bones. LI4 is purported to have analgesic properties and is commonly used for dental pain, headache and general analgesia. LI4 was chosen as the control point because it was close to PC7 and has analgesic properties. Identical methods of needling were used at both PC7 and LI4. The remaining two studies used acupuncture at the affected plantar fascia sites without any distal acupoints; ${ }^{(9,11)}$ Kumnerddee et al used 2-6 needles, while Ebrahim et al did not mention the number of needles used. Karagounis et al used both plantar fascia and distal acupoints (up to 12 acupoints from a list of 20 acupoints) in their treatment arm. ${ }^{(10)}$ This first combination of acupoints was used for six consecutive sessions. If no improvement was reported, another clinical examination was performed to choose alternative points for the next ten sessions.

Zhang et al compared an acupoint known to be specific for heel pain versus a sham acupoint with general analgesic properties. ${ }^{(8)}$ The other three studies, on the other hand, compared a local acupoint with standard conservative therapy. ${ }^{(9-11)}$ Standard therapy included ice, stretching, strengthening exercises and prefabricated insoles. Of the three studies, one had a third 
Table I. Summary of quality measures for the selected studies using the Delphi list.

\begin{tabular}{|c|c|c|c|c|c|c|c|c|c|c|}
\hline Study (yr) & Randomisation & $\begin{array}{l}\text { Allocation } \\
\text { concealment }\end{array}$ & $\begin{array}{l}\text { Similar } \\
\text { baseline }\end{array}$ & $\begin{array}{l}\text { Fulfilled } \\
\text { eligibility } \\
\text { criteria }\end{array}$ & $\begin{array}{l}\text { Blinded } \\
\text { outcome } \\
\text { assessor }\end{array}$ & $\begin{array}{l}\text { Blinded } \\
\text { care } \\
\text { provider }\end{array}$ & $\begin{array}{l}\text { Blinded } \\
\text { patient }\end{array}$ & $\begin{array}{l}\text { Point estimate } \\
\text { measure of } \\
\text { variability }\end{array}$ & $\begin{array}{l}\text { Intention } \\
\text { to treat }\end{array}$ & Score (\%) \\
\hline Ebrahim et al, $2007^{(11)}$ & Yes & Unknown & Yes & Yes & Unknown & Unknown & No & Yes & Unknown & $4 / 9(44.4)$ \\
\hline Zhang et al, 2011 ${ }^{(8)}$ & Yes & Yes & Yes & Yes & Yes & No & Yes & Yes & Yes & $8 / 9(88.9)$ \\
\hline Karagounis et al, 2011(10) & Yes & Yes & Yes & Yes & Yes & No & No & Yes & Unknown & $6 / 9(66.7)$ \\
\hline Kumnerddee et al, $2012^{(9)}$ & Yes & Yes & Yes & Yes & Unknown & No & No & Yes & Yes & $6 / 9(66.7)$ \\
\hline
\end{tabular}

Table II. Key characteristics and findings of selected studies.

\begin{tabular}{|c|c|c|c|c|c|c|c|c|}
\hline \multirow[t]{2}{*}{ Study (yr) } & \multirow[t]{2}{*}{ Treatment tested } & \multirow[t]{2}{*}{ Study cohort } & \multirow[t]{2}{*}{ Dropout } & \multirow[t]{2}{*}{ Duration } & \multirow{2}{*}{$\begin{array}{l}\text { Outcome } \\
\text { measure }\end{array}$} & \multicolumn{2}{|c|}{ Study arm } & \multirow[t]{2}{*}{ Pain score reduction } \\
\hline & & & & & & Intervention group & Control group(s) & \\
\hline $\begin{array}{l}\text { Ebrahim } \\
\text { et al, } \\
2007^{(11)}\end{array}$ & $\begin{array}{l}\text { Electro- } \\
\text { acupuncture at } \\
\text { plantar fascia }\end{array}$ & $\begin{array}{l}\mathrm{n}=23(9 \mathrm{~F}, 14 \mathrm{M}) \\
\text { Age range: } 33-53 \mathrm{yr}\end{array}$ & None & $8 w k$ & VAS & $\begin{array}{l}\text { A: Electro-acupuncture + } \\
\text { plantar fascia stretch + } \\
\text { Achilles tendon stretch } \\
+ \text { prefabricated insoles }\end{array}$ & $\begin{array}{l}\text { Control B: Same as } \\
\text { A, except without } \\
\text { electro-acupuncture } \\
\text { Control C: } \\
\text { Prefabricated } \\
\text { insoles only }\end{array}$ & $\begin{array}{l}\text { Reduction in VAS scores compared to baseline: } \\
\text { Intervention group A: } 3.872(p<0.0001) \\
\text { Control group B: } 0.84(p<0.05) \\
\text { Control group C: } 0.08(p>0.05) \\
\text { Comparison of mean VAS score reduction between } \\
\text { groups: } \\
\text { A vs. B: } 3.425(p<0.001) \\
\text { A vs. C: } 4.063(p<0.001) \\
\text { B vs. C: } 0.638(p>0.05)\end{array}$ \\
\hline $\begin{array}{l}\text { Zhang et al, } \\
2011^{(8)}\end{array}$ & $\begin{array}{l}\text { Acupuncture at } \\
\text { acupoints distal to } \\
\text { the plantar fascia }\end{array}$ & $\begin{array}{l}\mathrm{n}=53(39 \mathrm{~F}, 14 \mathrm{M}) \\
\text { Age range: } 44-52 \mathrm{yr}\end{array}$ & $\begin{array}{l}3 \text { from } \\
\text { control, } \\
3 \text { from } \\
\text { treatment } \\
\text { arms }\end{array}$ & $\begin{array}{l}1 \mathrm{mth} \\
3 \mathrm{mth} \\
6 \mathrm{mth}\end{array}$ & VAS & $\begin{array}{l}\text { Real acupuncture at } \\
\text { the PC7 acupoint } \\
\text { (located on the } \\
\text { palmar midpoint } \\
\text { of the wrist crease) }\end{array}$ & $\begin{array}{l}\text { Sham acupuncture } \\
\text { treatment at the } \\
\text { LI4 acupoint } \\
\text { (located between } \\
\text { the first and } \\
\text { second metacarpal } \\
\text { bones) }\end{array}$ & $\begin{array}{l}\text { Significant difference in reduction in VAS scores in } \\
\text { favour of the intervention group at } 1 \mathrm{mth} \\
\text { Morning pain: } 22.6 \pm 4.0 \text { vs. } 12.0 \pm 3.0 \\
\text { Overall pain: } 20.3 \pm 3.7 \text { vs. } 9.5 \pm 3.6 \\
\text { Pressure pain threshold: } 145.5 \pm 32.9 \text { vs. }-15.5 \pm 39.4 \\
\text { No significant difference found at } 3 \mathrm{mth} \text { and } 6 \mathrm{mth}\end{array}$ \\
\hline $\begin{array}{l}\text { Karagounis } \\
\text { et al, } \\
2011^{(10)}\end{array}$ & $\begin{array}{l}\text { Acupuncture } \\
\text { at plantar fascia } \\
\text { and distal } \\
\text { acupoints }\end{array}$ & $\begin{array}{l}\mathrm{n}=38(0 \mathrm{~F}, 38 \mathrm{M}) \\
\text { Age range: } 32-41 \mathrm{yr}\end{array}$ & None & $\begin{array}{l}4 \text { wk } \\
\text { and } \\
8 \text { wk }\end{array}$ & $\begin{array}{l}\text { PFPS } \\
\text { (includes } \\
\text { VAS) }\end{array}$ & $\begin{array}{l}\text { Conservative therapy } \\
\text { (ice therapy, NSAIDs, } \\
\text { stretching and } \\
\text { strengthening) + } \\
\text { acupuncture }\end{array}$ & $\begin{array}{l}\text { Conservative } \\
\text { therapy (ice } \\
\text { therapy, NSAIDs, } \\
\text { stretching and } \\
\text { strengthening) }\end{array}$ & $\begin{array}{l}\text { Significant difference in reduction in PFPS scores in } \\
\text { favour of the intervention group at } 8 \text { wk } \\
\text { Comparison of PFPS after } 4 \text { wk: } \\
\text { Control group: } 55.1 \\
\text { Intervention group: } 54.2(p>0.05) \\
\text { Comparison of PFPS after } 8 \text { wk: } \\
\text { Control group: } 46.2 \\
\text { Intervention group: } 34.3 \\
(p<0.05)\end{array}$ \\
\hline $\begin{array}{l}\text { Kumnerddee } \\
\text { et al, } 2012^{(9)}\end{array}$ & $\begin{array}{l}\text { Electro-acupuncture } \\
\text { at plantar fascia }\end{array}$ & $\begin{array}{l}\mathrm{n}=30(27 \mathrm{~F}, 3 \mathrm{M}) \\
\text { Age range: } 41-62 \mathrm{yr}\end{array}$ & $\begin{array}{l}6 \text { from } \\
\text { control } \\
\text { arm }\end{array}$ & 5 wk & VAS & $\begin{array}{l}\text { Conservative therapy } \\
\text { (oral analgesics and } \\
\text { stretching) } \\
+ \text { electro-acupuncture }\end{array}$ & $\begin{array}{l}\text { Conservative } \\
\text { therapy (oral } \\
\text { analgesics and } \\
\text { stretching) }\end{array}$ & $\begin{array}{l}\text { Significant difference in reduction in } \\
\text { VAS scores in favour of the intervention group } \\
\text { Intervention group: } 6.00 \pm 1.69 \text { vs. } 1.89 \pm 1.59 \\
\text { Control group: } 6.27 \pm 2.34 \text { vs. } 5.40 \pm 2.26\end{array}$ \\
\hline
\end{tabular}

F: female; M: male; NSAIDs: nonsteroidal anti-inflammatory drugs; PFPS: Plantar Fasciitis Pain/Disability Scale; VAS: visual analogue scale 
treatment arm that included patients for whom only prefabricated insoles were used. ${ }^{(11)}$ Kumnerddee et al allowed participants to use oral rescue analgesics, ${ }^{(9)}$ while Karagounis et al was found to have included the nonsteroidal anti-inflammatory drug diclofenac (75 mg twice daily for 15 days) as part of standard therapy. ${ }^{(10)}$ Meanwhile, Ebrahim et al specifically discouraged their participants from commencing any new treatments during the trial, such as anti-inflammatory medication, ${ }^{(11)}$ and Zhang et al, while advising participants to abstain from other forms of treatment, requested to be informed of any necessary analgesic use by the participants. ${ }^{(8)}$

In Karagounis et al's study, all 38 participants were active, amateur, male recreational athletes aged $32-41$ years, who practised their preferred sport $2-3$ times a week. ${ }^{(10)}$ Two studies recruited participants who were predominantly women and aged 31-62 years, from their respective rehabilitation outpatient and orthopaedic departments..$^{(9,11)}$ Zhang et al was found to have made announcements about their study in the local newspapers and at various community centres for recruitment of participants. ${ }^{(8)}$ Their study cohort was predominantly women aged 44-52 years.

In Kumnerddee et al's study, the inclusion criteria included failure of at least six weeks of conservative therapy (such as medication, heel cushion and stretching exercises). ${ }^{(9)}$ Ebrahim et al did not mention whether participants had engaged in any standard treatment prior to acupuncture, but excluded participants if they had received a corticosteroid injection within the past three months. ${ }^{(11)}$ Patients were concurrently encouraged not to commence any new treatment during the trial, such as antiinflammatory medication, but the study did not mention if anyone eventually did so. Zhang et al reported that most participants had received some form of treatment prior to entering the trial, but did not specify the nature of such treatment. ${ }^{(8)}$ Karagounis et al stated that none of their participants had received any previous treatment. ${ }^{(10)}$

For measurement of outcome, three studies used the visual analogue scale (VAS). ${ }^{(8,9,11)}$ Karagounis et al used the Plantar Fasciitis Pain/Disability Scale (PFPS), ${ }^{(10)}$ as it could be administered in any setting and could differentiate between plantar fascia pain and other pathologies causing heel pain. It also allowed physicians to perform a more descriptive and exclusive analysis of plantar fascia pain for the evaluation of therapeutic treatment than with the 100-point VAS. Interestingly, the latter study still included the VAS as part of its assessment.

Karagounis et al reported that three patients in the treatment group had headaches and dizziness, while one had loss of strength in the legs and mild local oedema around the area of needling. ${ }^{(10)}$ Kumnerddee et al noted that three patients had post-treatment soreness. ${ }^{(9)}$ Zhang et al reported several adverse reactions other than pain, such as mild oedema around the area of needling (PC7: 2, LI4: 5), bruising (PC7: 4, LI4: 5) and one patient with a 'distressed sensation' in the chest. ${ }^{(8)}$

The reviewed studies briefly mentioned that their respective acupuncturist was a well-trained and experienced professional, ${ }^{(10)}$ a registered Chinese medicine practitioner with two years of clinical experience, ${ }^{(8)}$ and a physiatrist who had completed a two- year training course from China with an additional six years of experience in acupuncture. ${ }^{(9)}$ Only Ebrahim et al did not mention the qualifications of their acupuncturist. ${ }^{(11)}$

There were several challenges involved in designing clinical trials to show the specificity of acupoints, since acupuncture often involves multiple acupoints. Although there may be a specific effect for a group of acupoints, it is not possible to isolate the therapeutic effect to just one acupoint. ${ }^{(8)}$ Furthermore, since the mechanism of acupuncture is not clear, an arbitrarily chosen control acupoint or non-acupoint may in fact produce the same physiological responses and have the same effectiveness as the test acupoint. Therefore, in order to examine the specificity of acupoints, it would be desirable to compare studies in which treatment was performed using a single acupoint with a distinct mechanism of action.

The number of participants (range 23-53) was small in all studies and the types of controls employed varied. Only one study (i.e. Zhang et al) studied real versus sham acupuncture at sites distal to the plantar fascia. ${ }^{(8)}$ The three other studies did not involve sham acupuncture, instead comparing acupuncture with standard treatment modalities, and hence blinding of participants could not be performed; this may have introduced expectation and assessment bias. Karagounis et al used both plantar fascia and distal acupoints, and allowed a change in the number of acupoints after six sessions of therapy if there was no improvement. ${ }^{(10)}$

Only two studies indicated their criteria for the achievement of adequate acupuncture therapy. ${ }^{(8,10)}$ In these studies, the 'Deqi' sensation was felt by participants and this was accepted as indicating successful depth of needle puncture. One study opined that the few statistical differences between its two groups at the three- and six-month post-treatment intervals may be due to the self-limiting nature of the disease or because participants had received other modalities of treatment during the follow-up period. ${ }^{(8)}$ There was also no documentation of analgesic medications being washed out before enrolment. Relief may also have been due to psychological and nonspecific physiological responses, such as an unintended generalised analgesic effect at the sham acupoint that was nearly as effective as treatment at the real acupoint. Also, the scoring system used in the Delphi list assumes that each criterion is equally weighted, but this may not necessarily be true.

Several mechanisms have been proposed to explain acupuncture's pain-relieving effects, including central opioid pain inhibition, ${ }^{(12)}$ the diffuse noxious inhibitory control (DNIC) system $^{(13)}$ and anti-inflammation. ${ }^{(14,15)}$ The process of needle insertion in any part of the body may alleviate pain through the mechanisms of opioids or DNIC, ${ }^{(12,16)}$ and the anti-inflammatory action of acupuncture may be generalised throughout the body. Indeed, it is often asked whether needles must be inserted into specific sites to have the best effect. Furthermore, only a few studies have showed the specificity of an acupoint in painful conditions; ${ }^{(17,18)}$ the majority of studies have shown acupoint specificity in non-painful conditions. ${ }^{(19-23)}$

Prolonged or repeated stimulation habituates neurons in the thalamus to a state of hyperexcitability, which leads to a state of 
chronic pain. ${ }^{(24)}$ Under these circumstances, the stimulation of specific acupoints may alter the excitability of hyperexcitable neurons in the thalamic focus. Interestingly, the centre of the wrist crease on the palmar aspect, where PC7 is located, is an anatomical mirror site of the heel.

Studies have suggested that since the endogenous opioid system and the DNIC mechanisms are both fast and short-acting, these mechanisms may not lend any important contribution to the slow onset and gradual time course of acupuncture's painrelieving effects. ${ }^{(12,25)}$ It is probable that different mechanisms are involved in the acupuncture treatment of different painful conditions. For example, the effect noticed for PC7 in the treatment of heel pain could be an anti-inflammatory one, instead of an analgesic action, which was previously observed for LI4. ${ }^{(26,27)}$

Several theories have been proposed to explain the effects of electro-acupuncture. In addition to the inflammation brought about by plantar fasciitis, the condition causes myofascial pain due to the development of trigger points in the foot muscles. Researchers have suggested that these points can be deactivated by acupuncture, with electrical stimulation providing an 'additive' effect. ${ }^{(28,29)}$ Deactivation of trigger points could also relieve the noxious stimulation, leading to central sensitisation in the spinal cord and central nervous system. Since there is scientific evidence supporting a link between electrical stimulation of acupuncture points and the release of endorphins, these researchers also theorised that electro-acupuncture could activate the body's pain relief system, increasing the concentration of endorphins in the central nervous system and decreasing the amount of pain signals that arrive at the spinal cord level. ${ }^{(30,31)}$

The present study was not without limitations. As a single author performed this review, the possibility of bias in study selection and appraisal, which could have impacted its results, cannot be disregarded. Also, only two databases were used for the literature searches and only studies published in the English language were researched.

Notwithstanding its limitations, the key takeaway messages from this study are:

- $\quad$ Further studies with larger sample sizes that compare inert placebos, such as sham acupuncture, conventional treatment and a pure control group with no treatment as parallel arms, are recommended.

- These studies should apply uniform and consistent methods of acupuncture application throughout the study course.

- Detailed information regarding the qualifications and experience of the acupuncturists involved should be made available.

- $\quad$ The study duration should be extended to a minimum of six months in order to study the longer-term effects of acupuncture.

- A better grading system should be considered to measure the quality of studies that cannot possibly ensure blinding of assessor and participants, as is the case for acupuncture, instead of trying to fit such studies into existing grading systems. A modular grading system that allows configuration to suit the type of study being attempted could be designed.
- Future studies could include objective measures of plantar fasciitis healing and treatment efficacy, such as ultrasonographic measurement of plantar fascia thickness, in addition to VAS scores.

- $\quad$ Future acupuncture-related research should consider using the STRICTA (Standards for Reporting Interventions in Clinical Trials of Acupuncture) 2010 reporting guidelines. ${ }^{(32)}$ These provide a detailed checklist to ensure completeness, transparency, accuracy of interpretation and replicability.

- $\quad$ For future reviews, Chinese research databases such as the Chinese Academic Literature database and Wanfang Data could be included in the search for related articles. These non-English databases were excluded in the present review, as the author is not conversant with the Chinese language.

In conclusion, acupuncture may be a safe and effective treatment modality for the short-term management of plantar fasciitis. Four studies have shown a significant reduction in pain during 4-8 weeks of therapy compared to standard therapy or sham acupuncture. However, the heterogeneity of these studies limits the formation of a definitive conclusion regarding the effectiveness of acupuncture to reduce pain in patients with plantar fasciitis in the longer term, and further research is required.

\section{REFERENCES}

1. Riddle DL, Schappert SM. Volume of ambulatory care visits and patterns of care for patients diagnosed with plantar fasciitis: a national study of medical doctors. Foot Ankle Int 2004; 25:303-10.

2. Thomas JL, Christensen JC, Kravitz SR, et al; American College of Foot and Ankle Surgeons Heel Pain Committee. The diagnosis and treatment of heel pain: a clinical practice guideline-revision 2010. J Foot Ankle Surg 2010; 49(3 Suppl):S1-19.

3. Karabay $\mathrm{N}$, Toros $\mathrm{T}$, Hurel C. Ultrasonographic evaluation in plantar fasciitis. J Foot Ankle Surg 2007; 46:442-6.

4. Goff JD, Crawford R. Diagnosis and treatment of plantar fasciitis. Am Fam Physician 2011; 84:676-82.

5. Peeraully T, Hameed S, Cheong PT, et al. Complementary therapies in hemifacial spasm and comparison with other movement disorders. Int J Clin Pract 2013; 67:801-6.

6. Tan MG, Win MT, Khan SA. The use of complementary and alternative medicine in chronic pain patients in Singapore: a single-centre study. Ann Acad Med Singapore 2013; 42:133-7.

7. Verhagen $\mathrm{AP}$, de Vet HC, de Bie RA, et al. The Delphi list: a criteria list for quality assessment of randomized clinical trials for conducting systematic reviews developed by Delphi consensus. J Clin Epidemiol 1998; 51:1235-41.

8. Zhang SP, Yip TP, Li QS. Acupuncture treatment for plantar fasciitis: a randomised controlled trial with six months follow up. Evid Based Complement Alternat Med 2011; 2011:154108.

9. Kumnerddee W, Pattapong N. Efficacy of electro-acupuncture in chronic plantar fasciitis: a randomized controlled trial. Am J Chin Med 2012; 40:1167-76.

10. Karagounis P, Tsironi M, Prionas G, Tsiganos G, Baltopoulos P. Treatment of plantar fasciitis in recreational athletes: two different therapeutic protocols. Foot Ankle Spec 2011; 4:226-34.

11. Ebrahim AH, Ahmed GM, Elsayed E, Sarhan R. Effect of electro acupuncture TENS, stretching exercises and prefabricated insole in patients with plantar fasciitis. Sci J Al-Azhar Med Fac 2007; 28:1-10.

12. Han JS. Acupuncture and endorphins. Neurosci Lett 2004; 361:258-61.

13. Carlsson C. Acupuncture mechanisms for clinically relevant longterm effects--reconsideration and a hypothesis. Acupunct Med 2002; 20:82-99.

14. Zhang SP, Zhang JS, Yung KK, Zhang HQ. Non-opioid-dependent antiinflammatory effects of low frequency electroacupuncture. Brain Res Bull 2004; 62:327-34.

15. Zijlstra FJ, van den Berg-de Lange I, Huygen FJ, Klein J. Anti-inflammatory actions of acupuncture. Mediators Inflamm 2003; 12:59-69. 
16. Le Bars D, Dickenson AH, Besson JM. Diffuse noxious inhibitory controls (DNIC). II. Lack of effect on non-convergent neurones, supraspinal involvement and theoretical implications. Pain 1979; 6:305-27.

17. Chen L, Tang J, White PF, et al. The effect of location of transcutaneous electrical nerve stimulation on postoperative opioid analgesic requirement: acupoint versus nonacupoint stimulation. Anesth Analg 1998; 87:1129-34

18. Itoh K, Katsumi $\mathrm{Y}$, Kitakoji $\mathrm{H}$. Trigger point acupuncture treatment of chronic low back pain in elderly patients--a blinded RCT. Acupunct Med 2004; 22:170-7.

19. Alkaissi A, Evertsson K, Johnsson VA, Ofenbartl L, Kalman S. P6 acupressure may relieve nausea and vomiting after gynecological surgery: an effectiveness study in 410 women. Can J Anaesth 2002; 49:1034-9.

20. Che-Yi C, Wen CY, Min-Tsung K, Chiu-Chung H. Acupuncture in haemodialysis patients at the Quchi (LI11) acupoint for refractory uraemic pruritus. Nephrol Dial Transplant 2005; 20:1912-5.

21. Middlekauff HR, Hui K, Yu JL, et al. Acupuncture inhibits sympathetic activation during mental stress in advanced heart failure patients. J Card Fail 2002; 8:399-406.

22. Turgut S, Ozalp G, Dikmen S, et al. Acupressure for postoperative nausea and vomiting in gynaecological patients receiving patient-controlled analgesia. Eur J Anaesthesiol 2007; 24:87-91.

23. Wang SM, Kain ZN. P6 acupoint injections are as effective as droperido in controlling early postoperative nausea and vomiting in children. Anesthesiology 2002; 97:359-66.
24. Lee TN. Thalamic neuron theory: theoretical basis for the role played by the central nervous system (CNS) in the causes and cures of all diseases. Med Hypotheses 1994; 43:285-302.

25. Calvino B, Villanueva L, Le Bars D. The heterotopic effects of visceral pain: behavioural and electrophysiological approaches in the rat. Pain 1984; 20:261-71.

26. Chapman CR, Benedetti C, Colpitts YH, Gerlach R. Naloxone fails to reverse pain thresholds elevated by acupuncture: acupuncture analgesia reconsidered. Pain 1983; 16:13-31.

27. Wang B, Tang J, White PF, et al. Effect of the intensity of transcutaneous acupoint electrical stimulation on the postoperative analgesic requirement. Anesth Analg 1997; 85:406-13.

28. Perez-Millan R, Foster L. Low-frequency electroacupuncture in the management of refractory plantar fasciitis: a case series. Med Acupunct $2001 ; 13: 47-9$.

29. Devitt M. Electroacupuncture for plantar fasciitis. In: Acupuncture Today 2001; 2. Available at: http://www.acupuncturetoday.com/archives2001/ dec/12plantar.html. Accessed January 6, 2014.

30. Hong CZ. Myofascial trigger points: pathophysiology and correlation with acupuncture points. Acupunct Med 2000; 18:41-7.

31. Tillu A, Gupta S. Effect of acupuncture treatment on the heel pain due to plantar fasciitis. Acupunct Med 1998; 16:66-8.

32. Standards for Reporting Interventions in Controlled Trials of Acupuncture. Checklist for STRICTA 2010. Available at: http://www.stricta.info/checklist. html. Accessed April 25, 2016 